\title{
Long term survival in primary pulmonary hypertension
}

\section{Halank, C Marx, G Hoeffken}

Heart 2004;90:e40 (http://www.heartjnl.com/cgi/content/full/90/7/e40). doi: 10.1136/hrt.2004.035725

\begin{abstract}
The mean survival of patients with severe primary pulmonary hypertension (PPH) is $<3$ years without appropriate treatment. There are no long term reports on the spontaneous course of mild PPH over a longer period. Stable long term follow up is described of a 39 year old patient with PPH without treatment over a 30 year period. PPH had been diagnosed 30 years previously after right heart catheterisation (mean pulmonary artery pressure $35 \mathrm{~mm} \mathrm{Hg}$ ) and 30 years later, repeated measurements showed nearly unchanged haemodynamic parameters. Further examinations confirmed the diagnosis of PPH. It is suggested that PPH with modestly limited physical activity (New York Heart Association functional class II) does not always seem to coincide with progression of the disease and, therefore, it may be feasible to withhold treatment while closely monitoring these patients.
\end{abstract}

$\mathrm{P}$ rimary pulmonary hypertension ( $\mathrm{PPH})$ is a disease of unknown origin. It is characterised by a progressive increase in pulmonary arterial pressures. Individual mortality is associated with variables of right ventricular dysfunction. The mean survival of patients with severe PPH is $<3$ years without appropriate medical treatment. ${ }^{1}$ To our knowledge, there are no long term reports on the spontaneous course of mild PPH over a period of three decades in the literature.

We present a stable long term follow up of a young patient with PPH without specific medical treatment over a period of 30 years.

\section{CASE REPORT}

Thirty years ago, a now 39 year old woman was evaluated by right heart catheterisation for the first time. At that time, the 9 year old girl had exertional dyspnoea and fatigue. Height and weight were in the normal range. The girl had no signs of cyanosis and there were no other abnormal findings. Physical examination showed a mild right parasternal systolic murmur over the fifth intercostal space. Spirometry, lung auscultation, and neuropsychiatric status were normal. Appetite suppressant use was ruled out. At this time, right heart catheterisation and oxymetry showed no left to right cardiac shunting. Mean pulmonary arterial pressure was $35 \mathrm{~mm} \mathrm{Hg}$, mean right atrial pressure was $4 \mathrm{~mm} \mathrm{Hg}$, pulmonary arterial wedge pressure was $8 \mathrm{~mm} \mathrm{Hg}$, and mixed venous oxygen saturation was $67 \%$. Owing to these findings, PPH was suspected. The young girl was advised to avoid physical efforts and was released from school sports but received no specific treatment because none was available. Her further physical development was unremarkable. She finished school prematurely because of decreased capability of mental concentration. Later, the patient was able to manage easy physical and mental work without problems.

Thirty years later, routine chest radiography showed a globular heart and decreased retrosternal air space. Because of this chest radiograph, the patient was admitted to our hospital to initiate treatment for the known pulmonary hypertension. On presentation, she had no clinical signs of right heart decompensation. Except for the known heart murmur, her physical examination was unremarkable. She had exertional dyspnoea, which only moderately limited her physical activity (New York Heart Association (NYHA) functional class II). Transthoracic and transoesophageal echocardiography showed an increased ventricular systolic pressure (estimated at $60 \mathrm{~mm} \mathrm{Hg}$ ), excluding cardiac causes of pulmonary hypertension. The ventilation-perfusion scan showed no pulmonary thromboemboli. Pulmonary function testing, polysomnography, and abdomen sonography showed no pathological evidence. Serological tests, including parameters for systemic autoimmune diseases, liver disease, hyperparathyroidism, and HIV infection, were within normal ranges. Repeated right heart catheterisation 30 years after the first catheter showed nearly unchanged haemodynamic parameters (mean pulmonary arterial pressure $32 \mathrm{~mm} \mathrm{Hg}$; mean right atrial pressure $3 \mathrm{~mm} \mathrm{Hg}$; and pulmonary arterial wedge pressure $7 \mathrm{~mm} \mathrm{Hg}$ ). Cardiac index, which had not been measured 30 years previously, was $3.3 \mathrm{l} / \mathrm{min}$. After inhaling a total dose of $5 \mu \mathrm{g}$ iloprost through a mouthpiece with a jet nebuliser (IloNeb/Aerotrap, Nebu-Tec, Elsenfeld, Germany) and the Pulmocar Akku compressor (Sanesco Medizintechnik, Vienna, Austria) as described previously, ${ }^{2}$ mean pulmonary artery pressure decreased to $20 \mathrm{~mm} \mathrm{Hg}$. Table 1 lists haemodynamic data before and after inhalation of iloprost. During cycle spiroergometry at a working rate of $130 \mathrm{~W}$, she reached a peak oxygen uptake of $22 \mathrm{ml} / \mathrm{kg} / \mathrm{min}$. She was able to walk $485 \mathrm{~m}$ in six minutes. Genetic testing did not show mutations in the BMPR2 gene locus. Treatment with a calcium channel blocker (amlodipine $10 \mathrm{mg} /$ day) was started but had to be stopped because of side effects of hypotension and oedema.

Table 1 Cardiopulmonary haemodynamic data at baseline after 30 years of known primary pulmonary hypertension and at the end of inhalation of $5 \mu \mathrm{g}$ iloprost

\begin{tabular}{lcc}
\hline Parameter & Baseline & $\begin{array}{c}\text { At the end of inhalation } \\
\text { of } 5 \mu \mathrm{g} \text { iloprost }\end{array}$ \\
\hline PAPm $(\mathrm{mm} \mathrm{Hg})$ & 32 & 20 \\
PVR $\left(\right.$ dyn $\left.\cdot \mathrm{s} \cdot \mathrm{cm}^{-5}\right)$ & 339 & 178 \\
$\mathrm{Cl}\left(\mathrm{l} / \mathrm{min} / \mathrm{m}^{2}\right)$ & 3.3 & 3.5 \\
$\mathrm{RRm}(\mathrm{mm} \mathrm{Hg})$ & 81 & 82 \\
$\mathrm{SVR}\left(\mathrm{dyn} \cdot \mathrm{s} \cdot \mathrm{cm}^{-5}\right)$ & 1058 & 1015 \\
$\mathrm{RAP}(\mathrm{mm} \mathrm{Hg})$ & 3 & 2 \\
$\mathrm{PCWP}(\mathrm{mm} \mathrm{Hg})$ & 7 & 6 \\
$\mathrm{SaO}_{2}($ volume\%) & 97 & 98 \\
$\mathrm{SvO}_{2}$ (volume\%) & 73 & 74
\end{tabular}

$\mathrm{Cl}$, cardiac index; PAPm, mean pulmonary arterial pressure; $\mathrm{PCWP}$ pulmonary capillary wedge pressure; PVR, pulmonary vascular resistance; $R A P$, right atrial pressure; $\mathrm{RRm}$, mean arterial pressure; $\mathrm{SaO}_{2}$, arterial oxygen saturation; $\mathrm{SvO}_{2}$, mixed venous oxygen saturation; SVR, systemic vascular resistance. 


\section{DISCUSSION}

In this case report we describe an untreated long term 30 year follow up of a patient with mild PPH without progression of the disease. In a non-randomised cohort trial the efficacy of high dose calcium channel blocker among patients with severe PPH and acute vasodilator responses was shown. ${ }^{3}$ Because of side effects, however, our patient could not be given the planned long term treatment with amlodipine. Randomised placebo controlled clinical trials have shown the clinical efficacy of oral beraprost sodium, ${ }^{4}$ the oral dual endothelin receptor antagonist bosentan, ${ }^{5}{ }^{6}$ inhaled iloprost, ${ }^{7}$ and subcutaneous treprostinil. ${ }^{8}$ Intravenous prostaglandins are an alternative for the treatment of severe pulmonary hypertension. ${ }^{9}$ Prostaglandins $^{10}$ endothelin receptor antagonists are now recommended for first line treatment of patients with severe PPH if no acute vasodilator response is present. Treatment recommendations for milder forms of PPH (NYHA class I and II) are lacking.

On the basis of the case presented here, we suggest that PPH with modestly limited physical activity (NYHA class II) does not always seem to coincide with progression of the disease. Therefore, it may be feasible, with close monitoring, to withhold treatment for these patients.

\section{ACKNOWLEDGEMENTS}

Dr Halank has received speaker's honorariums from Actelion and Schering.

\section{Authors' affiliations}

M Halank, C Marx, G Hoeffken, University Hospital Carl Gustav Carus, Internal Medicine I, Dresden, Germany
Correspondence to: Dr M Halank, University Hospital Carl Gustar Carus, Internal Medicine I, Fetscherstrasse 74, 01307 Dresden, Germany; Michael.Halank@uniklinikum-dresden.de

Accepted 17 March 2004

\section{REFERENCES}

1 D'Alonzo GE, Barst RJ, Ayres SM, et al. Survival in patients with primary pulmonary hypertension: results from a national prospective registry. Ann Intern Med 1991;115:343-9.

2 Olschewski H, Rohde B, Behr J, et al. Pharmacodynamics and pharmacokinetics of inhaled iloprost, aerosolized by three different devices, in severe pulmonary hypertension. Chest 2003;124:1294-304

3 Rich S, Kaufmann E, Levy PS. The effect of high doses of calcium-channel blockers on survival in primary pulmonary hypertension. N Engl J Med 1992;327:76-81.

4 Galie N, Humbert M, Vachiery JL, et al. Effects of beraprost sodium, an oral prostacyclin analogue, in patients with pulmonary arterial hypertension: a randomised, double-blind, placebo-controlled trial. J Am Coll Cardiol 2002;39:1496-502.

5 Channick RN, Simonneau G, Sitbon O, et al. Effects of the dual endothelin receptor antagonist bosentan in patients with pulmonary hypertension: a randomised placebo-controlled study. Lancet 2001;358:1119-23.

6 Rubin $\mathrm{L}$, Badesch DB, Barst R, et al. Bosentan therapy for pulmonary arterial hypertension. N Engl J Med 2002;346:896-903.

7 Olschewski H, Simmonneau G, Galie N, et al. Inhaled iloprost for severe pulmonary hypertension. N Engl J Med 2002;347:322-9.

8 Simmonneau G, Barst RJ, Galie N, et al. Continuous subcutaneous infusion of treprostinil, a prostacyclin analogue, in patients with pulmonary arterial hypertension. Am J Respir Crit Care Med 2002;165:800-4.

9 Barst RJ, Rubin L, Long WA, et al. A comparison of continuous intravenous epoprostenol (prostacyclin) with conventional therapy for primary pulmonary hypertension. N Engl J Med 1996;334:296-302.

10 Hoeper MM, Spiekerkoetter E, Westerkamp V, et al. Intravenous iloprost for treatment failure of aerosolised iloprost in pulmonary arterial hypertension. Eur Respir J 2002;20:339-43. 